\title{
The Chinese experience with anti-NMDAR encephalitis
}

\author{
Virginie Desestret ${ }^{1,2,3}$
}

${ }^{1}$ Institut NeuroMyogène, Equipe Synaptopathies et Autoanticorps (SynatAc), INSERM U1217/UMR CRS 5310, Lyon, France; ${ }^{2}$ French Reference Center on Paraneoplastic Neurological Syndrome, Hospices civils de Lyon, Lyon, France; ${ }^{3}$ University of Lyon, Université Claude Bernard Lyon 1 , Lyon, France

Correspondence to: Docteur Virginie Desestret. Neurocognition, Hôpital Neurologique Pierre Wertheimer, 59 Boulevard Pinel, 69677 Bron Cedex, France. Email: virginie.desestret@chu-lyon.fr.

Provenance and Peer Review: This article was commissioned and reviewed by the Section Editor Dr. Jinming Han (Department of Clinical Neuroscience, Center for Molecular Medicine, Karolinska Institutet, Karolinska University Hospital, Stockholm, Sweden).

Comment on: Xu X, Lu Q, Huang Y, et al. Anti-NMDAR encephalitis: A single-center, longitudinal study in China. Neurol Neuroimmunol Neuroinflamm 2020. doi: 10.1212/NXI.0000000000000633.

Submitted Jan 11, 2020. Accepted for publication Jan 28, 2020.

doi: 10.21037/atm.2020.01.127

View this article at: http://dx.doi.org/10.21037/atm.2020.01.127

Anti-NMDA receptor (NMDAR) encephalitis is a severe autoimmune neuropsychiatric disorder characterized by the presence in CSF of anti-NMDAR autoantibodies of the IgG subtype (1-3). It is a recently described disease since the first descriptions date from 2005 (4). Since then, several hundred cases have been reported around the world, and, although the clinical and epidemiological presentation is globally consistent regardless of the population studied (i.e., severe neuropsychiatric symptoms usually affecting children and young adults with a female prevalence and often a good response to treatment), there are differences in their clinical characteristics between ethnicities and countries (5-9). This could suggest variable immunopathological mechanisms possibly influenced by the genetic background or by different environmental factors.

This is the reason why the recent publication by the Peking Union Medical College Hospital of the historical Chinese cohort of 220 anti-NMDAR encephalitis patients diagnosed between 2011 and 2017 in China is of primary importance (10). Indeed, to date, available data regarding the clinical characteristics and long-term prognosis of Chinese anti-NMDAR patients come from only a limited number of reports of small sample size (11-14), and in the largest international cohort published (577 patients from 35 countries), only 8 Chinese patients were included (5). This precluded any conclusion as to the particular characteristics of the disease in this population which is now made possible by comparison with reported cohorts of comparable size, for instance the French cohort (15-18) and the international benchmark (5).

In terms of clinical presentation, not surprisingly, neuropsychiatric symptoms are largely dominated, here as elsewhere, by behavioral and psychotic disorders and seizures [developed by respectively $82 \%$ and $81 \%$ of the Chinese patients, and for comparison by $81 \%$ and $78 \%$ of the French cases (16)]. The first difference observed is epidemiological: effectively if the classic median age of 21 years is the same among reported series, the large female predominance [around $80 \%(5,18)$ ], is less marked here (65\%). This higher proportion of male cases probably accounts for another feature of Chinese patients who less frequently present an associated neoplasm. Knowing that the vast majority of the tumors associated with antiNMDAR encephalitis are ovarian teratomas, it is quite logical that a smaller proportion of Chinese patients $(19.5 \%)$ present an underlying neoplasm, compared to the $38 \%$ reported, for example, in the international reference study (5). However, this frequency of paraneoplastic cases is comparable to that described in the French cohort $[25 \%,(18)]$ and half of that reported among the Asian group in the international study (44\%) which mainly included Japanese and Korean patients (5). This feature may suggest different immunopathological mechanisms at the origin of the immunization against the NMDA receptor which remain to be identified. As the authors suggest, in tumor-negative patients, herpes 
simplex virus (HSV) infection could be the possible trigger that can be underdiagnosed for financial reasons, as most of the patients received empirical treatment without a definite diagnosis of HSV encephalitis which requires PCR testing. Because paraneoplastic cases seem relatively rare, a systematic search for viral triggers in this population could be very interesting.

The most astonishing characteristic in this large cohort is certainly the very largely favorable outcome of Chinese patients at 12 months, since more than $92 \%$ of them reach a satisfactory functional score [modified Rankin Scale (mRS) score $<2$ ], whereas such a good outcome is obtained in only $78 \%$ of the international patients at 24 months (5) and $82 \%$ of the French patients at 12 months $(15,16)$. This better short-term outcome is probably partly related to the rapid management of the diagnosis by this national referral center since the authors report an impressive median 2 weeks from onset to diagnosis and concomitant initiation of treatment. Another explanation for this favorable outcome could be a lower clinical severity of the disease; only 133/220 (60\%) of patients were severe ( $\mathrm{mRS}$ score $\geq 4$ ) during the course of the disease, while $86 \%$ of patients in the international cohort and $73 \%$ of the French patients reached a mRs score of $5(5,15)$. Consistently, the Chinese study found a low frequency of intensive care unit admission (31\% versus $75 \%$ in the other studies). This is explained by limited availability of medical recourses and concern of expenses, but it seems to be also related to a lower severity of the antiNMDAR encephalitis in Chinese patients. Interestingly, these patients relapse as frequently, if not more, than the others $[17.3 \%$ versus $15.5 \%$ in France $(15)$ and $8 \%$ in the international cohort (5)], and the only factor associated with relapse that has been identified is the time to treatment, but not the treatment regimen nor the tumor status. This last point contrasts with the international study that has shown that patients without a tumor had a higher frequency of relapse than did those with a tumor, and that the use of immunotherapy was associated with fewer relapses. It is likely that the low frequency of tumors in Chinese patients leads to a lack of statistical power due to a too small number of patients in the tumor group.

The satisfactory outcome of Chinese anti-NMDAR encephalitis patients is certainly related to an effective management, comprising combined therapy of re-enforced first-line therapy and long-term immunotherapy. Indeed, repeated first-line immunotherapy was frequently used, whereas second-line immunotherapy was administered to a small portion of patients (7\%), owing to the off-label use of rituximab (RTX) for auto-immune encephalitis in China, cost, hospitalization requirements, and concerns about side effects. However, long-term immunotherapy was provided to $53.2 \%$ of patients, including mycophenolate mofetil (MMF) to $49.5 \%$ versus $6 \%$ in the international cohort (5) and $28 \%$ of the French patients (15). Given these results, one can naturally ask the question of the value of a second line of RTX immunotherapy in particular compared to a chronic immunosuppression by steroid sparing agents such as MMF or azathioprine (AZA), which is notably less expensive and well supported. The Chinese experience incites to further investigate the place of each of these therapies, maybe according to the severity of the disease and the presence or not of a controllable autoimmunity trigger.

The main limit of this real-life study is maybe its partially retrospective nature, however, the hindsight taken by $\mathrm{Xu}$ et al. on the evolution of practices under constrains, in particular financial and organizational, as illustrated by an eloquent figure on the percentages of correct diagnosis at the initial hospital visit over misdiagnosis over time, is particularly appreciated. Clearly, this work adds to the current knowledge of anti-NMDAR encephalitis and paves the way for future multicenter studies with more comprehensive evaluations, especially long-term cognitive ones.

\section{Acknowledgments}

We gratefully acknowledge Philip Robinson for English language editing (Direction de la Recherche Clinique, Hospices civils de Lyon) and Dr. Véronique Rogemond for her review.

Funding: None.

\section{Footnote}

Conflicts of Interest: The author has completed the ICMJE uniform disclosure form (available at http://dx.doi. org/10.21037/atm.2020.01.127). The author has no conflicts of interest to declare.

Ethical Statement: The author is accountable for all aspects of the work in ensuring that questions related to the accuracy or integrity of any part of the work are appropriately investigated and resolved.

Open Access Statement: This is an Open Access article distributed in accordance with the Creative Commons Attribution-NonCommercial-NoDerivs 4.0 International 
License (CC BY-NC-ND 4.0), which permits the noncommercial replication and distribution of the article with the strict proviso that no changes or edits are made and the original work is properly cited (including links to both the formal publication through the relevant DOI and the license). See: https://creativecommons.org/licenses/by-nc-nd/4.0/.

\section{References}

1. Dalmau J, Gleichman AJ, Hughes EG, et al. Anti-NMDAreceptor encephalitis: case series and analysis of the effects of antibodies. Lancet Neurol 2008;7:1091-8.

2. Dalmau J, Lancaster E, Martinez-Hernandez E, et al. Clinical experience and laboratory investigations in patients with anti-NMDAR encephalitis. Lancet Neurol 2011;10:63-74.

3. Dalmau J, Tüzün E, Wu H, et al. Paraneoplastic anti-Nmethyl-D-aspartate receptor encephalitis associated with ovarian teratoma. Ann Neurol 2007;61:25-36.

4. Vitaliani R, Mason W, Ances B, et al. Paraneoplastic encephalitis, psychiatric symptoms, and hypoventilation in ovarian teratoma. Ann Neurol 2005;58:594-604.

5. Titulaer MJ, McCracken L, Gabilondo I, et al. Treatment and prognostic factors for long-term outcome in patients with anti-NMDA receptor encephalitis: an observational cohort study. Lancet Neurol 2013;12:157-65.

6. Lim JA, Lee ST, Jung KH, et al. Anti-N-methyl-daspartate receptor encephalitis in Korea: clinical features, treatment, and outcome. J Clin Neurol 2014;10:157-61.

7. Bartolini L, Muscal E. Differences in treatment of antiNMDA receptor encephalitis: results of a worldwide survey. J Neurol 2017;264:647-53.

8. Iizuka T, Sakai F, Ide T, et al. Anti-NMDA receptor encephalitis in Japan: long-term outcome without tumor removal. Neurology 2008;70:504-11.

9. Irani SR, Bera K, Waters $\mathrm{P}$, et al. N-methyl-D-aspartate

Cite this article as: Desestret V. The Chinese experience with anti-NMDAR encephalitis. Ann Transl Med 2020;8(11):718. doi: 10.21037/atm.2020.01.127 antibody encephalitis: temporal progression of clinical and paraclinical observations in a predominantly non-paraneoplastic disorder of both sexes. Brain 2010;133:1655-67.

10. Xu X, Lu Q, Huang Y, et al. Anti-NMDAR encephalitis: A single-center, longitudinal study in China. Neurol Neuroimmunol Neuroinflamm 2020;7:e633.

11. Zhang W, Cui L, Wang W, et al. Early identification of anti-NMDA receptor encephalitis presenting cerebral lesions in unconventional locations on magnetic resonance imaging. J Neuroimmunol 2018;320:101-6.

12. Zhang Y, Liu G, Jiang M, et al. Clinical Characteristics and Prognosis of Severe Anti-N-methyl-d-aspartate Receptor Encephalitis Patients. Neurocrit Care 2018;29:264-72.

13. Guan W, Fu Z, Zhang H, et al. Non-tumor-Associated Anti-N-Methyl-D-Aspartate (NMDA) Receptor Encephalitis in Chinese Girls With Positive Anti-thyroid Antibodies. J Child Neurol 2015;30:1582-5.

14. Huang $\mathrm{X}$, Fan $\mathrm{C}, \mathrm{Wu} \mathrm{J}$, et al. Clinical analysis on anti-Nmethyl-D-aspartate receptor encephalitis cases: Chinese experience. Int J Clin Exp Med 2015;8:18927-35.

15. Viaccoz A, Desestret V, Ducray F, et al. Clinical specificities of adult male patients with NMDA receptor antibodies encephalitis. Neurology 2014;82:556-63.

16. Desestret V, Chefdeville A, Viaccoz A, et al. CSF IgA NMDAR antibodies are potential biomarkers for teratomas in anti-NMDAR encephalitis. Neurol Neuroimmunol Neuroinflamm 2015;2:e166.

17. Zekeridou A, Karantoni E, Viaccoz A, et al. Treatment and outcome of children and adolescents with $\mathrm{N}$-methyl-D-aspartate receptor encephalitis. J Neurol 2015;262:1859-66.

18. Bost C, Chanson E, Picard G, Meyronet D, et al. Malignant tumors in autoimmune encephalitis with antiNMDA receptor antibodies. J Neurol 2018;265:2190-200. 